\title{
ORTA VE BATI ANADOLU ENDEMIK İÇSU BALIKLARININ GÜNÜMÜZDEKİ DAĞILIMLARI VE KORUMA STATÜLERİ
}

\author{
Ali İLHAN ${ }^{1}$, Süleyman BALIK, Hasan M. SARI
}

\section{ÖZET}

Bu çalışmada, Orta ve Batı Anadolu içsularında dağılım gösteren endemik balık taksonlarının güncel dağılım alanlarının tespit edilmesi, populasyonların durumu ve tehdit unsurlarının belirlenmesi amaçlanmıştır. $\mathrm{Bu}$ amaçla, 2005, 2006 ve 2007 yılları yaz aylarında 7 saha çalışması gerçekleştirilmiştir. Bu saha çalışmalarında, 268 istasyonda balık örneklemeleri yapılmıştır. Örneklemelerde elektroşoker, farklı göz açıklığındaki ağlar ve tül ığrıp kullanılmıştır. Çalışma sonucunda Orta ve Batı Anadolu içsuları için endemik özellikte olan 32 takson tespit edilmiştir. Elde edilen birey sayıları ve saha çalışmalarındaki gözlemler ışığında bazı türlerin "IUCN Kırmızı Liste"ye göre tehdit kategorileri için, değişiklik önerisinde bulunulmuştur. Çalışma alanında, türlerin devamlılı̆̆ını tehdit eden en önemli unsurların sınırlı yaşam alanı, kirlilik, barajlar, habitat kaybı, yabancı türlerin varlığı ve kuraklık olduğu sonucuna varılmıştır.

Anahtar Kelimeler: Endemik, Anadolu, Kırmızı Liste, yabancı türler

\footnotetext{
${ }^{1}$ Ege Üniversitesi Su Ürünleri Fakültesi, Su Ürünleri Temel Bilimler Bölümü İçsular Biyolojisi Anabilim Dalı, 35100, Bornova/İzmir alilhan73@gmail.com, tel: 02323115345
} 


\title{
RECENT DISTRIBUTION AND CONSERVATION STATUS OF ENDEMIC FRESHWATER FISHES FROM CENTRAL AND WESTERN ANATOLIA
}

\begin{abstract}
The present study, aimed to determine current distribution areas, population status and the risk factors of the endemic fish taxa in Central and Western Anatolia freshwaters. For this purpose seven fieldworks were carried out during the summer months in years of 2005, 2006 and 2007. Fish samples were collected from 268 stations. Electroshock, gill nets of different mesh and seine nets were used for sampling. In Central and Western Anatolia, 32 endemic taxa were obtained from freshwaters. According to obtained individual numbers and field observations, some changes were suggested for IUCN Red List categories of certain species. The most important threats for survival of the species were considered as limited habitat, pollution, dams, habitat loss, presence of exotic species and drought in the study area.
\end{abstract}

Key Words: Endemic, Anatolia, Red List, alien species

\section{GİRIŞ}

Anadolu, geçirdiği jeolojik olayların fazlalığı ve klimatolojik özelliklerinin yanısıra kıtalar arasında yer almasından ötürü farklı kökenli canlıların uğrak ve geçiş yeri konumundadır (Demirsoy, 2002). Tatlısu balıkları açısından bakıldığında ise, tür çeşitliliğindeki en büyük etken Anadolu'nun Miyosen başlarına kadar sular altında olması gösterilebilir. Anadolu'nun Miyosenin başlarından itibaren yükselmeye başlaması ile birlikte, boğazlar sistemi ve dağ sıraları gibi yalıtımların oluşması söz konusu çeşitlilikte önemli rol oynamıştır (Demirsoy, 2002). Dolayısıyla, Miyosen'den itibaren oluşmaya başlayan Anadolu tatlısu balık faunası ile ilgili olarak, 1835 yılında Abbot ile başlayan çalışmalar birçok yerli ve yabancı araştırıcı tarafından günümüze kadar sürdürülmüştür. Türkiye içsu balıkları üzerine yüzlerce çalışma yapılmışken, bu çalışmalar daha ziyade fauna tespiti ve ticari değere sahip türlerin biyolojik özelliklerinin belirlenmesi 
üzerine gerçekleştirilmiştir. Endemik balık taksonları ise daha sınırlı sayıda çalışmada ele alınmış olup, ilk çalışma Van Gölü'nden Alburnus tarichi çalışması ile Deyrolle (1872)'e aittir. Sonraki yıllarda endemik taksonların Anadolu içsularından bildirimleri devam etmiş olup, Battalgil (1944), Karaman (1969, 1971), Banarescu vd. (1978), Erk'akan (1983), Balık (1988, 1995), Kuru (1984, 2004), Bogustkaya (1992, 1995, 1996, 1997a, 1997b), Küçük ve İkiz (1993, 2004), Erk'akan vd. (1999), Wildekamp vd. (1999), Bogustkaya vd. (2000), Küçük (2006), Fricke vd. (2007), Geldiay ve Balık (2007), Yeğen vd. (2007, 2008), Smith ve Darwall (2005) yaptıkları çalışmalarla yeni bilgiler sunmuşlardır.

Son dönemlerde yaşanan iklimsel değişimler, su kullanımında yapılan yanlışlıklar, su kaynaklarının kirletilmesi, yasadışı veya bilinçsiz avcılık faaliyetleri, sucul kaynaklara yapılan müdaheleler gibi birçok olumsuzluk, hemen tamamı çok sınırlı yaşam alanlarına sahip olan endemik balık türlerinin devamlılığını sorgular hale getirmiştir. Nitekim, Anadolu'nun önemli doğal göllerinden biri olan Beyşehir Gölü'nden bilinen Alburnus akili türünün doğada nesli tükenmiştir.

Bu çalışmada, yukarıda bahsedilen olumsuz durumların sonucunda, Türkiye'nin Marmara, Ege, Akdeniz ve İç Anadolu bölgelerindeki endemik içsu balıklarına ait taksonların günümüzdeki durumlarının saptanması amaçlanmıştır. Ayrıca, balık türlerinin devamlılığı açısından tehdit oluşturan unsurların da belirlenmesine çalışılmıştır.

\section{MATERYAL ve YÖNTEM}

Çalışmaya konu olan endemik balık türlerinin örneklenmesi için 2005, 2006 ve 2007 yıllarının ilkbahar ve yaz aylarında 7 arazi çalışması gerçekleştirilmiştir. Söz konusu arazi çalışmaları 68 gün sürmüş olup, 34 ili kapsayan 278 istasyondan balık örnekleri toplanmıştır. Örnekleme yapılan istasyonların koordinatları "Macellan Explorist 500" model GPS cihazı ile belirlenmiştir. Balık örneklemeleri "SAMUS 725 G" model elektroşoker, farklı göz açıklığındaki ağlar ve tül ığrıp kullanılarak gerçekleştirilmiştir. Yakalanan balıklar fotoğraflanarak, \%4'lük formaldehit ile tespit edilmiştir. Laboratuvara getirilen balık örneklerinin tür teşhisleri yapılarak, Ege Üniversitiesi, Su Ürünleri Fakültesi Müzesi İçsu Balıkları Kolleksiyo- 
nunda (ESFM-PISI) koruma altına alınmıştır. Balıkların tür teşhislerinde Ahnelt (1995), Bogutskaya (1992, 1996, 1997), Bogutskaya vd. (2000), Elvira (1987), Erk'akan vd. (1999), Freyhof ve Özuluğ (2006, 2009), Geldiay ve Balık (2007), Karaman (1969, 1971), Kuru (1980), Wildekamp vd. (1999)'nin yapmış oldukları çalışmalardan yararlanılmıştır.

\section{BULGULAR}

Çalışma sonucunda Anadolu'nun orta ve batı kesimlerinde dağılım gösteren endemik içsu balıklarından 32 tür tespit edilmiştir. Tespit edilen türler ile, IUCN Kırmızı liste kategorileri, başlıca tehditler, tespit edildikleri lokaliteler ile birey sayıları aşağıda listelenmiştir.

Familia: Salmonidae

Salmo platycephalus Behnke, 1968

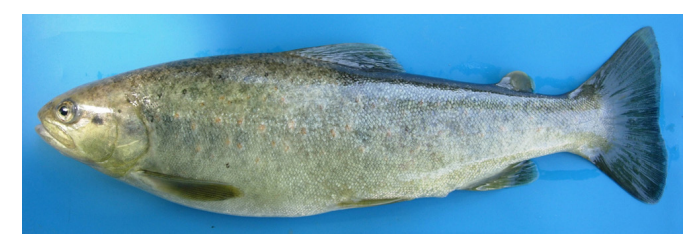

IUCN Kırmızı liste kategorisi: CR B1ab (v)+2ab (v)

Tehditler: Yabancı tür varlığı (Oncorhynchus mykiss) ve yasadışı avcılık.

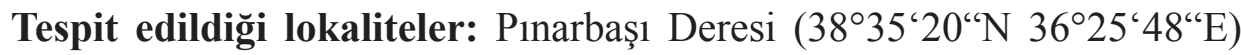
(Pınarbaşı-Kayseri) 6 birey, Sarı Çayı (3822‘02“N 36²6‘32“E) (SarıKayseri) 9 birey.

Familia: Cyprinidae

Alburnus baliki Bogutskaya, Küçük\&Ünlü, 2000

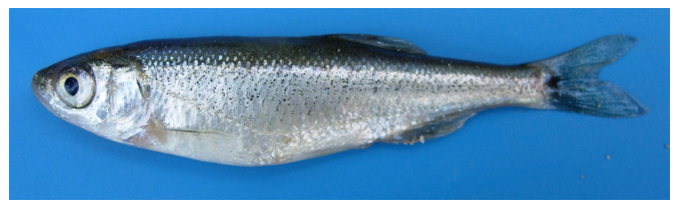

IUCN Kırmızı liste kategorisi: EN B2ab (i, ii, iii, iv, v)

Tehditler: Kirlilik, barajlar, su kaynaklarının kullanımı ve iklimsel değişimler sonucu yağışların azalması (kuraklık). 
Tespit edildiği lokaliteler: Aksu Çayı (36 57'52'N 3054'11'E) (AksuAntalya) 4 birey, Karg1 Çayı (36 55'11'”N 31²4'23'E) (ManavgatAntalya) 22 birey.

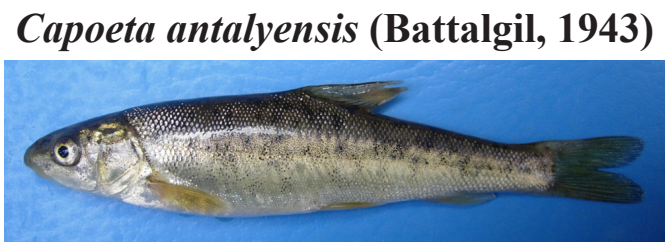

IUCN Kırmızı liste kategorisi: VU B1ab (i,ii,iii,iv,v) + 2ab (i,ii,iii,iv,v)

Tehditler: Kirlilik ve barajlar.

Tespit edildiği lokaliteler: Köprü Çayı (3657'13’”N 31¹0’29”E) (Serik-

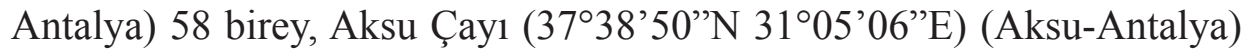
24 birey.

Capoeta angorae (Hankó, 1925)

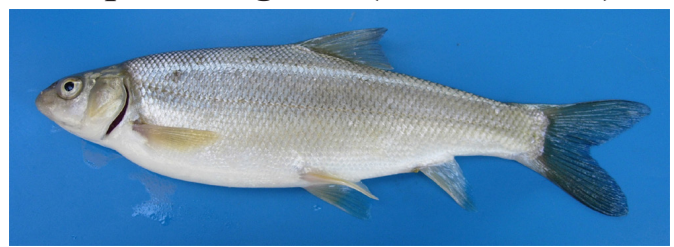

\section{IUCN Kırmızı liste kategorisi: DD}

Tehditler: Nispeten geniş bir dağılım alanına sahip olması dolayısı ile diğer türler kadar olmasa da barajların varlığı.

Tespit edildiği lokaliteler: Aksu Çayı (3657'52'N 3054'11'E) (AksuAntalya) 3 birey, Karg1 Çayı $\left(36^{\circ} 55^{\prime} 11^{\prime \prime} \mathrm{N} 31^{\circ} 24^{\prime} 23^{\prime \prime} \mathrm{E}\right)$ (ManavgatAntalya) 90 birey, Alara Çayı (36 $\left.41^{\prime} 29^{\prime \prime} \mathrm{N} 31^{\circ} 43^{\prime} 02^{\prime \prime} \mathrm{E}\right)$ (AlanyaAntalya) 39 birey, Dim Çayı (36 31'34'N 3203'32'E) (Alanya-Antalya) 3 birey, (3749'03'N 3056'43”E) Kapız Deresi (Eğirdir-Isparta) 67 birey, Deli Çay $\left(38^{\circ} 08^{\prime} 00^{\prime \prime} N 35^{\circ} 09^{\prime} 43^{\prime \prime}\right.$ ) (Hacibeyli-Niğde) 10 birey, Kocadere (37 $\left.03^{\prime} 18^{\prime \prime} \mathrm{N} \quad 33^{\circ} 20^{\prime} 48^{\prime \prime} \mathrm{E}\right)$ (Gülkaya-Karaman) 2 birey, Melendiz Çayı (3819'36”N 34¹4'26”E) (Gülağaç-Aksaray) 1 birey, Peçenek Deresi (38 57'11'N 33 33'10"E) (Şereflikoçhisar-Ankara) 15 birey, Sarı̈z Deresi (37 $47^{\prime} 46^{\prime \prime N} 31^{\circ} 48^{\prime} 02$ '”E) (Beyşehir-Konya) 31 birey, Berdan Çayı (3656’59”N 3453'38'E) (Tarsus-İçel) 15 birey, Ermenek Çayı (36 33'07’'N 32॰57'25’'E) (Ermenek-Karaman) 
4 birey, Kızılkırtık Deresi (3650’20”N 32³4'51'E) (Taşkent-Konya) 27 birey, Balcılar Deresi (36 $\left.57^{\circ} 03^{\prime \prime N} 32^{\circ} 32^{\prime} 10^{\prime \prime} \mathrm{E}\right)$ (Taşkent-Konya)

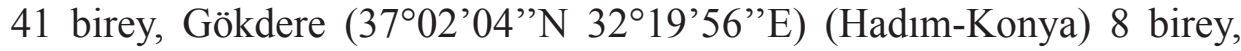
Delice Deresi (36 23'02'N 32 18’32”E) (Gazipaşa-Antalya) 57 birey, Bıçkıcı Deresi (36 21'32'”N 32²2’36”'E) (Gazipaşa-Antalya) 28 birey, Çörüş Deresi $\left(36^{\circ} 17^{\prime} 15^{\prime \prime} \mathrm{N} 32^{\circ} 22^{\prime} 26^{\prime \prime} \mathrm{E}\right)$ (Gazipaşa-Antalya) 82 birey, Kaladron Çay1 (3606’37'”N 32³4'21'”E) (Anamur-İçel) 7 birey, Anamur Çay1 (36 $\left.10^{\prime} 19^{\prime \prime} \mathrm{N} 32^{\circ} 53^{\prime} 48^{\prime \prime} \mathrm{E}\right)$ (Anamur-İçel) 115 birey, Çakıt Suyu (37³1'27’N 3443'58'"E) (Ulukışla-Niğde) 60 birey, Dadaloğlu Deresi (38 29'47'N 36 07'37'E) (Tomarza-Kayseri) 14 birey, Kurttepe Deresi $\left(38^{\circ} 35^{\prime} 08^{\prime} \mathrm{N} \quad 36^{\circ} 08^{\prime} 40^{\prime \prime} \mathrm{E}\right)$ (Pınarbaş1-Kayseri) 23 birey, Kabaktepe Deresi (3838'30’N 36²6'20”E) (Pınarbaşı-Kayseri) 12 birey, Sarız Çay1 (38 23'41'”N 36²7'12"E) (Sarız-Kayseri) 19 birey, Taşligeçit Deresi (3900'46”N 36³9’26”'E) (Pınarbaşı-Kayseri) 51 birey, Pınargözü Deresi (37046'57'N 35 54'31'E) (Feke-Adana) 19 birey, Asmaca Deresi (3749'21'”N 35 53'51'"E) (Feke-Adana) 13 birey, Ördekli Deresi (3829'42”'N 3646'54"E) (Afşin-Kahraman Maraş) 3 birey, Kızılcıksuyu Deresi (38 09'16”N 3642’28'”) (Göksun-Kahraman Maraş) 40 birey, Savrun Çayı (37²3'18'N 3604'49'"E) (Kadirli-Adana) 3 birey.

\section{Capoeta baliki Turan, Kottelat, Ekmekçi \& İmamoğlu, 2006}

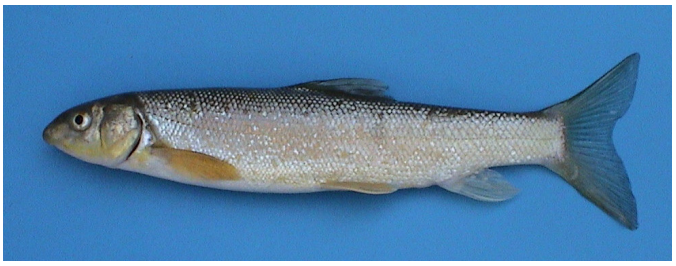

\section{IUCN Kırmızı liste kategorisi: LC}

Tehditler: Barajlar.

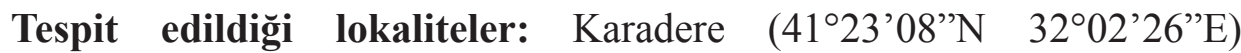
(Çaycuma-Zonguldak) 1 birey, Gerdek Deresi (41²2'01'N 31 $\left.{ }^{\circ} 59^{\prime} 54^{\prime \prime} \mathrm{E}\right)$ (Beycuma-Zonguldak) 3 birey, Döngeller Deresi (41 $\left.{ }^{\circ} 16^{\prime} 00^{\prime \prime} \mathrm{N} 31^{\circ} 58^{\prime} 43^{\prime \prime} \mathrm{E}\right)$ (Devrek-Zonguldak) 11 birey, Göynük Çayı (40²3'58’N 30³3'01'”E) (Göynük-Bolu) 2 birey, Nallı Deresi (40¹4'18'N 31²0'40”E) (NallıhanBolu) 15 birey, Aladağ Çayı (40²4'13”N 31³4'28”E) (Seben-Bolu) 20 birey, Mengen Çayı (4053'18’N 31 ${ }^{\circ} 58^{\prime} 09^{\prime}$ 'E) (Mengen-Bolu) 20 birey, Ulus Çayı (41³1'20’N 32³4’04’E) (Ulus-Bartın) 2 birey, Ova Çayı 


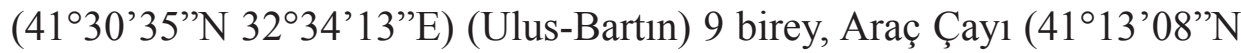

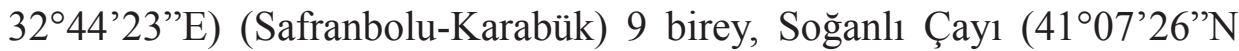

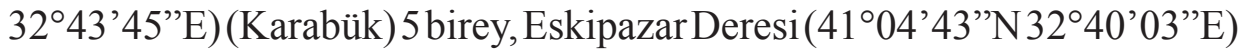
(Karabük) 6 birey, Çerkeş Çayı (4051'41’N 32³8’20”E) (Çerkeş-Çankırı) 10 birey, Bulak Çayı (40³0'55'N 32³6'44”E) (Kızılcahamam-Ankara) 8 birey, Kocaçay $\left(40^{\circ} 25^{\prime} 56^{\prime} \mathrm{N} 32^{\circ} 39^{\prime} 01^{\prime \prime} \mathrm{)}\right)$ (Kizılcahamam-Ankara) 1 birey, Bayındır Çayı (40¹9’21'N 32²7'53”E) (Kızılcahamam-Ankara) 20 birey, Süvari Deresi (40²' $\left.50^{\prime}{ }^{\circ} \mathrm{N} 32^{\circ} 06^{\prime} 07^{\prime \prime} \mathrm{E}\right)$ (Güdül-Ankara) 30 birey, Yalımkaya Deresi (39'59'13”N 31 '20'42”'E) (Mihaliççık-Eskişehir) 2 birey, Sarısu Çayı (3949’22”N 3009'15”E) (İnönü-Eskişehir) 20 birey, Porsuk Çayı (39 21 '43'N3003'04”'E)(Kütahya) 11 birey, Çamkışla Deresi

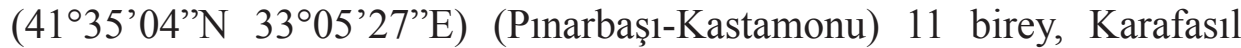

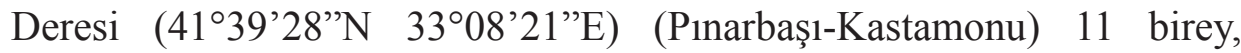
Devrekani Çayı (41 ${ }^{\circ} 40^{\prime} 08^{\prime}$ 'N 3309'40”E) (Pınarbaş1-Kastamonu) 2 birey, Derelitekke Deresi (41 $\left.{ }^{\circ} 43^{\prime} 38^{\prime \prime} \mathrm{N} 33^{\circ} 28^{\prime} 03^{\prime \prime} \mathrm{E}\right)$ (Azdavay-Kastamonu) 20

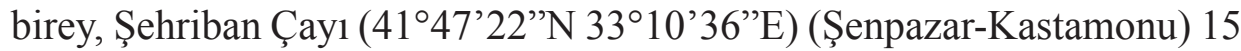
birey, Cide Deresi (4153'50’N 32 59'59”E) (Cide-Kastamonu) 5 birey,

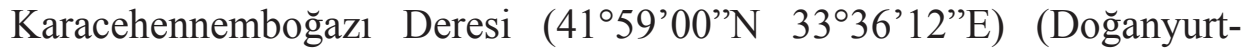
Kastamonu) 20 birey, Sakalar Deresi (41 $\left.{ }^{\circ} 58^{\prime} 38^{\prime \prime N} 33^{\circ} 43^{\prime} 38^{\prime \prime E}\right)$ (İnebolu-

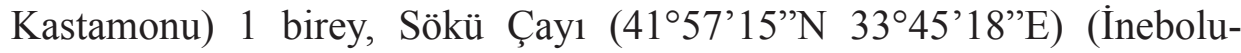

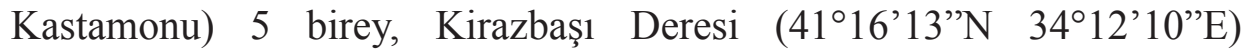

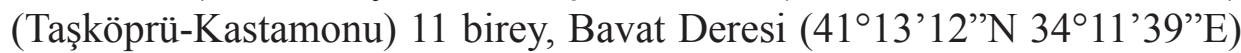

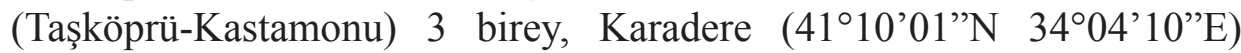
(Kastamonu) 1 birey, Devrez Çayı (4056’27’N 3353'52”E) (TosyaKastamonu) 20 birey.

\section{Capoeta bergamae Karaman, 1969}

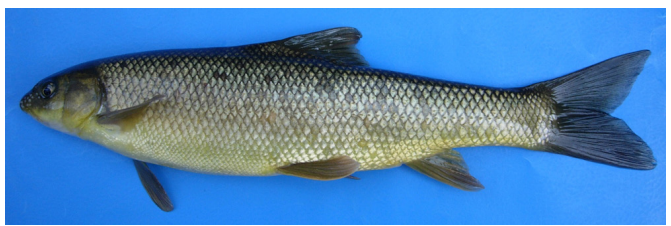

\section{IUCN Kırmızı liste kategorisi: NT}

Tehditler: Kirlilik, barajlar, su kaynaklarının kullanımı ve iklimsel değişimler sonucu yağışların azalması (kuraklık).

Tespit edildiği lokaliteler: Akpınar kaynakları (3841'40'”N 27058'40'E) (Gölmarmara-Manisa) 3 birey, Akçay Deresi (37¹3’31’N 2852’30”E) 
(Beyağaç-Denizli) 7 birey, Kocaçay (37¹3'06”N 2846’00”E) (Karacaören-Muğla) 3 birey, Dalaman Çayı (36 $\left.49^{\circ} 58^{\prime \prime N} 28^{\circ} 47^{\prime} 53^{\prime \prime E}\right)$ (Dalaman-Muğla) 1 birey.

Capoeta tinca (Heckel, 1843)

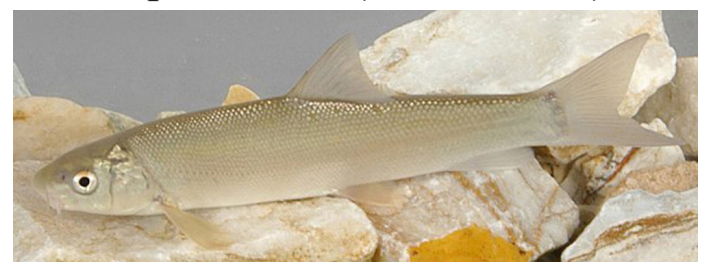

\section{IUCN Kırmızı liste kategorisi: LC}

Tehditler: Kirlilik, barajlar ve iklimsel değişimler sonucu yağışların azalması (kuraklık).

Tespit edildiği lokaliteler: Kocaçay $\left(40^{\circ} 03^{\prime} 51^{\prime \prime} \mathrm{N} \quad 27^{\circ} 54^{\prime} 51^{\prime \prime} \mathrm{E}\right)$

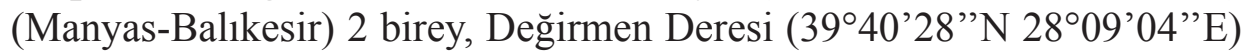
(Kepsut-Balıkesir) 44 birey, Simav Çayı (39²4'51'N 28 05'50"E) (Bigadiç-Balıkesir) 17 birey, Susurluk Nehri (3953'51'”N 2809'33"E)

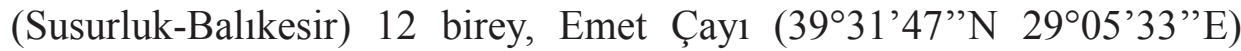
(Tavşanl1-Kütahya) 88 birey, Kaçak Deresi (39¹1'58”N 28 15'17'E)

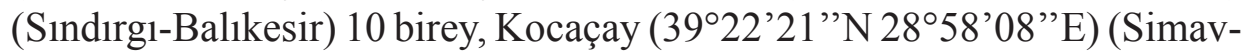

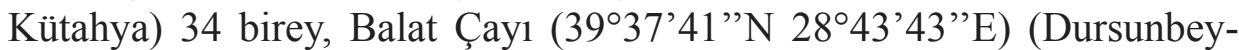
Balıkesir) 157 birey, Çiçekpınar Deresi (39॰31'16”N 2754'51'E) (Balıkesir) 38 birey, Üzümcü Deresi (39³3'35'N 2748'06'”E) (Balıkesir)

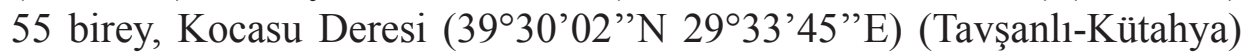
17 birey, Kirmasti Çayı (3956'09'N 28³2'24'”E) (Çavuşköy-Bursa)

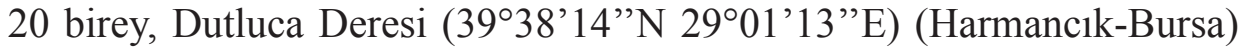
47 birey, Sadağ birey.

\section{Chondrostoma angorense Elvira, 1987}

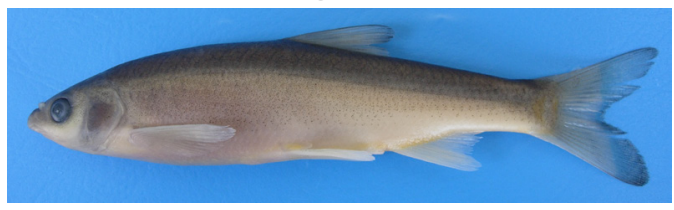

IUCN Kırmızı liste kategorisi: LC

Tehditler: Kirlilik ve barajlar. 
Tespit edildiği lokaliteler: Bulak Deresi (40³0'55'N 32॰36'44”E) (Kızılcahamam-Ankara) 4 birey, Seydi Çayı (39³0’35”N 3059’26”E) (Mahmudiye-Eskişehir) 2 birey.

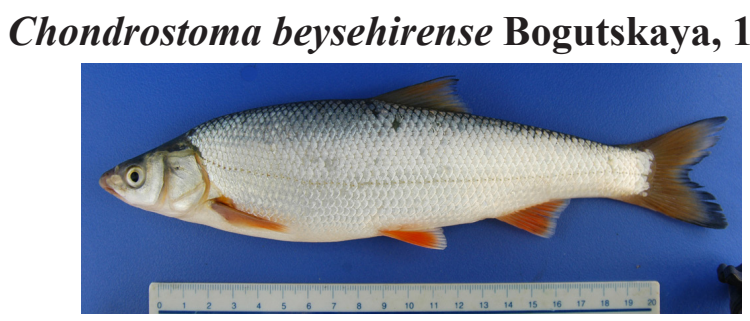

IUCN Kırmızı liste kategorisi: EN Blab (i,ii,iii,iv,v) + 2ab (i,ii,iii,iv,v)

Tehditler: Sınırlı yaşam alanı, yabancı tür varlığı (Sander lucioperca) ve kuraklik.

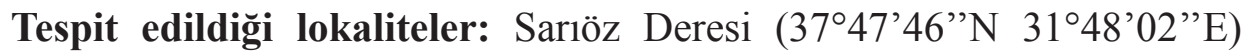
(Beyşehir-Konya) 4 birey.

\section{Chondrostoma fahirae (Ladiges, 1960)}

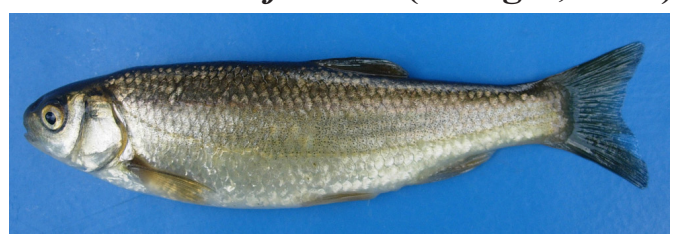

IUCN Kırmızı liste kategorisi: EN B2ab (i,ii,iii,iv,v)

Tehditler: Kirlilik, su kaynaklarının kullanımı ve iklimsel değişimler sonucu yağışların azalması (kuraklık).

Tespit edildiği lokaliteler: Dalaman Çayı (37¹4'23'N 29³1'53”E) (Çamköy-Gölhisar) 2 birey, Dalaman Çayı (37²0'43”N 29²5'47’E) (Acıpayam-Denizli) 2 birey, Dereboğazı Deresi (37²3'33”N 2949'58”E)

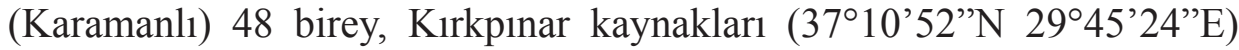
(Tefenni-Antalya) 37 birey, Akkaya Deresi (3754'01'N 34³3'59'E) (Bor-Niğde) 4 birey. 


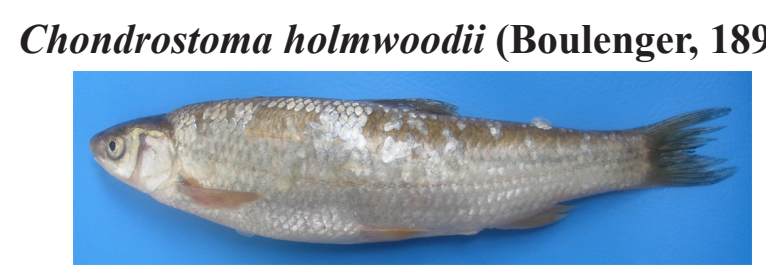

IUCN Kırmızı liste kategorisi: VU A2c; B2ab (i,ii,iii,iv,v)

Tehditler: Kirlilik, su kaynaklarının kullanımı, barajlar ve iklimsel değişimler sonucu yağışların azalması (kuraklık).

Tespit edildiği lokaliteler: Tahtalı Baraj Gölü (38 $\left(8^{\circ} 10^{\prime} 31^{\prime \prime N} 27^{\circ} 07^{\prime} 42^{\prime \prime} \mathrm{E}\right)$ (Menderes-İzmir) 25 birey, Şaşal Deresi (38 $11^{\prime} 50^{\prime \prime N} 27^{\circ} 09^{\prime} 32$ 'E) (Menderes-İzmir) 105 birey, Bulgurca Deresi (38¹1'43'” 2709'58'E) (Menderes-İzmir) 9 birey.

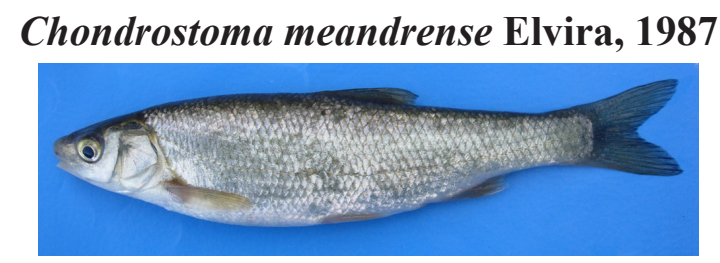

IUCN Kırmızı liste kategorisi: VU B1ab (ii, iii)+2ab (ii, iii)

Tehditler: Kirlilik, su kaynaklarının kullanımı, barajlar ve iklimsel değişimler sonucu yağışların azalması (kuraklık).

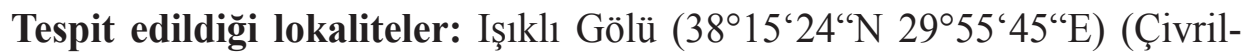

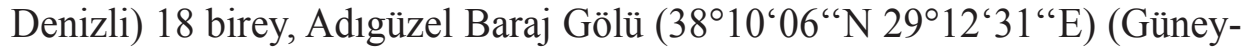
Denizli) 17 birey.

Gobio hettitorum Ladiges, 1960

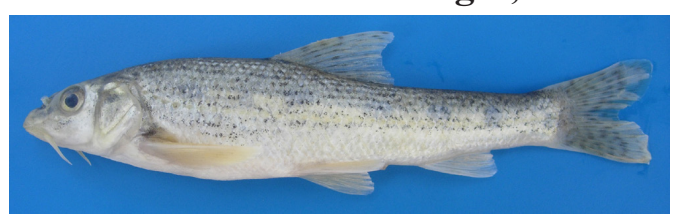

IUCN Kırmızı liste kategorisi: CR Blab (i,ii,iii,iv)

Tehditler: Sınırlı yaşam alanı, kuraklık.

Tespit edildiği lokaliteler: Gökdere (3703'18’'N 3320'48’E) (GülkayaKaraman) 12 birey. 


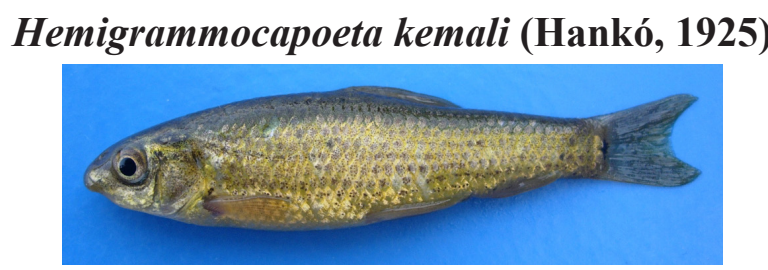

IUCN Kırmızı liste kategorisi: EN B1ab (i,ii,iii,iv,v) + 2ab (i,ii,iii,iv,v)

Tehditler: Habitat kaybı ve yabancı tür varlığı (Gambusia affinis, Carassius gibelio).

Tespit edildiği lokaliteler: İlırmak Deresi (37³0’36”N 31²7’26”E)

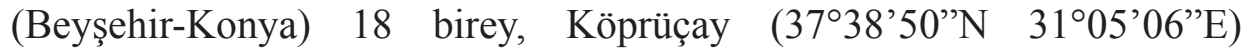
(Ayvalıpınar willage) 11 birey, Işıklı Gölü (38¹5’24”N 2955'45”E) (Çivril-Denizli) 290 birey.

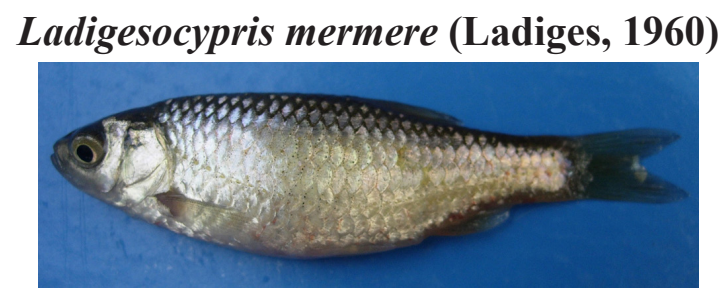

IUCN Kırmızı liste kategorisi: DD

Tehditler: Sınırlı yaşam alanı, yabancı tür varlığı (Carassius gibelio, Pseudorasbora parva).

Tespit edildiği lokaliteler: Akpınar kaynakları (3841'40'”N 2758'40"E) (Gölmarmara-Manisa) 20 birey.

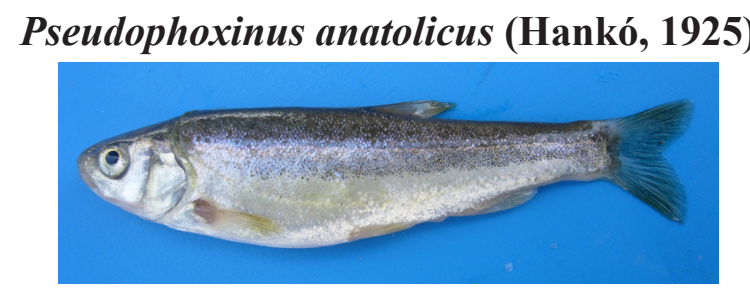

IUCN Kırmızı liste kategorisi: EN B2ab (i,ii,iii,iv,v)

Tehditler: Sınırlı yaşam alanı, kirlilik, kuraklık.

Tespit edildiği lokaliteler: Saltık Deresi (38²9'05'”N 3004'26”'E) (Sandıkl1-Afyonkarahisar) 8 birey, Yarışlı Gölü kaynakları (37³2’26”N 
2956'53”E) (Yeşilova-Burdur) 31 birey, Büyükçay kaynağı (37³1'14’N

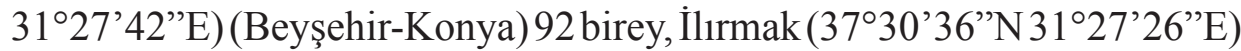
(Beyşehir-Konya) 138 birey, Beyşehir Gölü (3740'59’N 3126'27’E)

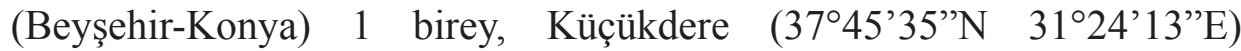
(Yenişarbademli-Isparta) 19 birey, Salur Deresi (38 $\left.02^{\circ} 08^{\prime \prime} \mathrm{N} 31^{\circ} 17^{\prime} 08^{\prime \prime} \mathrm{E}\right)$ (Şakrikaraağaç-Isparta) 71 birey.

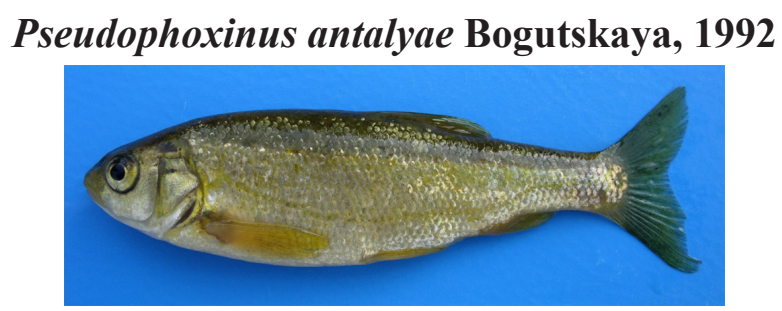

IUCN Kırmızı liste kategorisi: VU D2

Tehditler: Su kaynaklarının kullanımı, habitat değişimi, kirlilik.

Tespit edildiği lokaliteler: Kırkgöz kaynakları (3706’34”N 30³4'49”E) (Döşemealtı-Antalya) 129 birey.

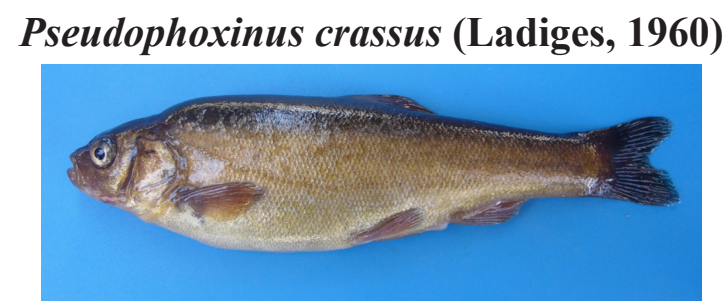

IUCN Kırmızı liste kategorisi: EN B2ab (i,ii,iii,iv)

Tehditler: Kuraklık ve su kaynaklarının kullanımı.

Tespit edildiği lokaliteler: İnsuyu kaynakları (3844'19’N 32॰42’36”E) (Cihanbeyli-Konya) 22 birey, Samsam Deresi (3907'08'N 32 $45^{\circ} 33$ 'E) (Kulu-Konya) 31 birey, Kozanlı Deresi (3902'14'”N 3248'37'E) (KuluKonya) 84 birey.

Pseudophoxinus egridiri (Karaman, 1972)

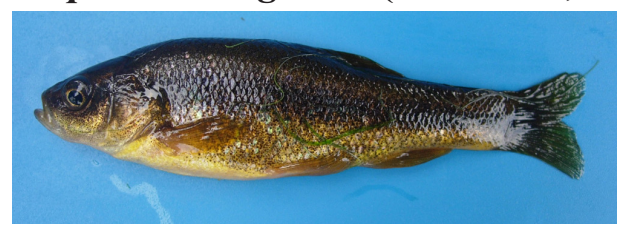


IUCN Kırmızı liste kategorisi: EN Blab (i,ii,iii,iv,v) + 2ab (i,ii,iii,iv,v)

Tehditler: Yabancı tür varlığı (Sander lucioperca, Carassius gibelio, Atherina boyeri), iklimsel değişimler sonucu yağışların azalması ve sınırlı yaşam alanı (kuraklık).

Tespit edildiği lokaliteler: Eğirdir Gölü (3807’22”N 3054’28”E) (Gelendost-Isparta) 82 birey.

\section{Pseudophoxinus fahrettini Freyhof \& Özuluğ, 2009}

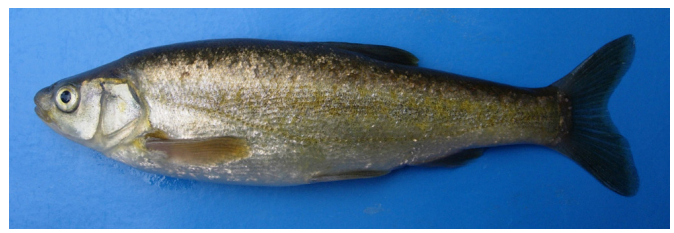

IUCN Kırmızı liste kategorisi: EN B2ab (ii,iii)

Tehditler: Su kaynaklarının kullanımı, barajlar ve iklimsel değişimler sonucu yağışların azalması (kuraklık).

Tespit edildiği lokaliteler: Köprüçay (37³8'29’N $\left.31^{\circ} 05^{\prime} 33^{\prime \prime} \mathrm{E}\right)$ (Ayvalıpınar kasabası) 89 birey

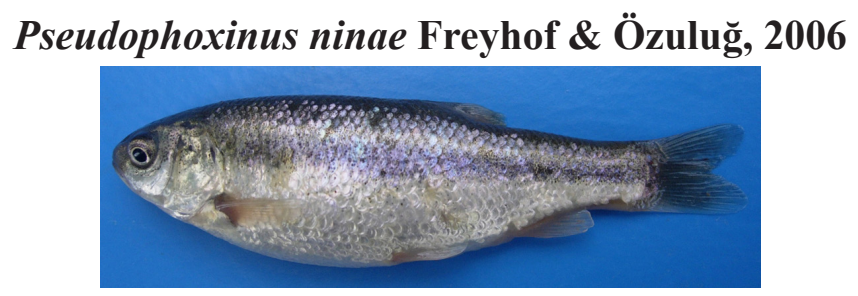

IUCN Kırmızı liste kategorisi: CR B1ab (ii,iii)

Tehditler: Su kaynaklarının kullanımı, barajlar, kirlilik ve iklimsel değişimler sonucu yağışların azalması (kuraklık).

Tespit edildiği lokaliteler: Dereboğazı Deresi (37²3'33'N 2949'58'E) (Karamanl1) 37 birey, Değirmendere (3731'02”N 29³8'26”E) (YeşilovaBurdur) 58 birey, Eren Çayı (37³0’09”N 3004’36”E) (Boğaziçi-Burdur) 2 birey. 


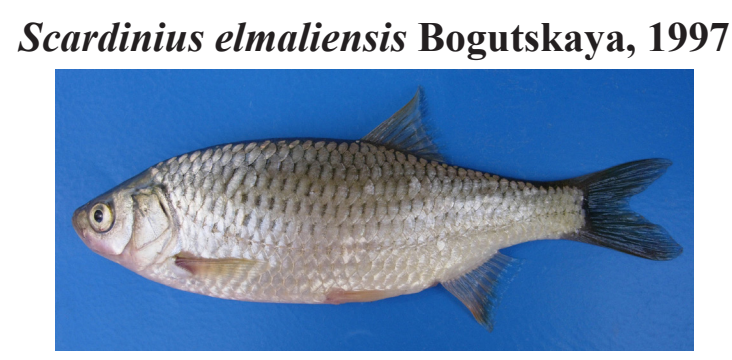

IUCN Kırmızı liste kategorisi: EN B1ab (i,ii,iii,iv) + 2ab (i,ii,iii,iv)

Tehditler: Su kaynaklarının kullanımı, barajlar ve iklimsel değişimler sonucu yağışların azalması (kuraklık).

Tespit edildiği lokaliteler: Avlan Gölü (36³4'15”N 2957'02”E) (Elmal1-Antalya) 21 birey.

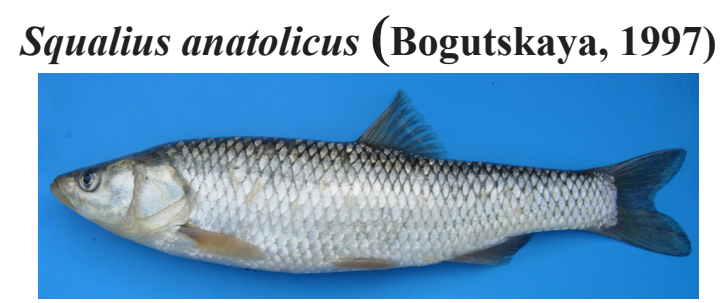

IUCN Kırmızı liste kategorisi: LC

Tehditler: Türün varlığına yönelik bir tehdit unsuru belirtilmemiştir.

Tespit edildiği lokaliteler: Büyükçay Deresi (37³2'46" N 31 $29^{\circ}$ '44" E) (Beyşehir-Konya) 14 birey, Salur Deresi (3802'08” N 31 ${ }^{\circ} 17^{\prime} 08^{\prime}$ " E) (Şakrikaraağaç-Isparta) 3 birey, Sarı̈z Deresi (3745'01'”N 3146’32”E) (Beyşehir-Konya) 12 birey, Çarşamba Deresi (37¹9'55”N 32²6’34”E) (Akören-Konya) 12 birey.

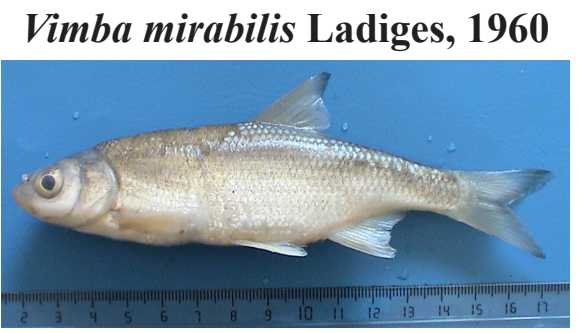

IUCN Kırmızı liste kategorisi: LC

Tehditler: Kirlilik, barajlar ve su kaynaklarının kullanımı. 


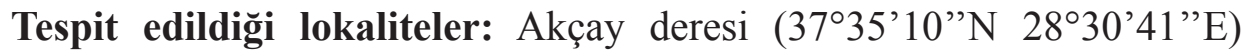
(Bozdoğan-Aydın) 52 birey, Kemer baraj gölü (37³2’33’'N 28 32'55'E) (Bozdoğan-Aydın) 44 birey.

Familia: Cobitidae

Cobitis bilseli Battalgil, 1942

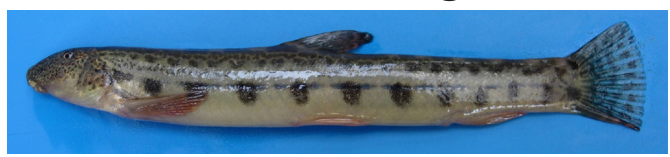

IUCN Kırmızı liste kategorisi: EN B1ab (ii,iii) + 2ab (ii,iii)

Tehditler: Yabanc1 tür varlığı (Sander lucioperca, Pseudorasobra parva, Knipowitschia caucasica, Alburnus escherichii) ve kurakl1k.

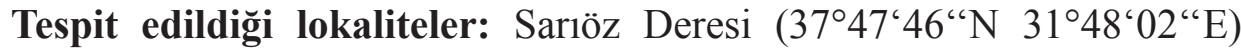
(Beyşehir-Konya) 38 birey.

Cobitis fahirae Erk'akan, Atalay-Ekmekçi \& Nalbant, 1998

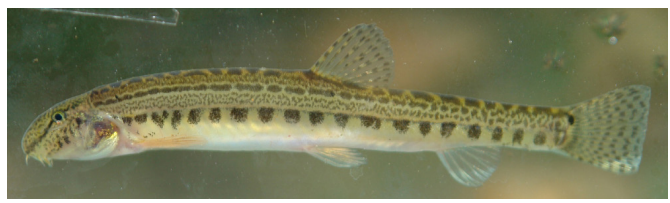

IUCN Kırmızı liste kategorisi: LC

Tehditler: Kirlilik ve su kaynaklarının kullanımı

Tespit edildiği lokaliteler: Koca Çay (4003'51 'N 2754'51' E) (ManyasBalıkesir) 15 birey, Tuzla Çayı (39³0’00”N 26¹9'59'E) (AyvacıkÇanakkale) 1 birey, Karamenderes Nehri (3949'05”N 26³7'00”E) (Bayramiç-Çanakkale) 10 birey, Ada Çayı (3948'11'N 2646'46”E) (Bayramiç-Çanakkale) 2 birey, Çakırköy Deresi (3956'43”N 2720'13”E) (Yenice-Çanakkale) 2 birey, Kocaçay Deresi (3950'06”N 27¹9'57'E) (Yenice-Çanakkale) 3 birey, Gönen Çayı (3958'48’N 27²7'24'E) (Yenice-Çanakkale) 62 birey, Kocaçay Deresi (40¹1'51'N 2721'28'E) (Biga-Çanakkale) 1 birey, Bakacak Deresi $\left(40^{\circ} 12^{\prime} 32^{\prime \prime} \mathrm{N} 2^{\circ} 03^{\prime} 31^{\prime \prime} \mathrm{E}\right)$ (Biga-Çanakkale) 17 birey, Bahçeli Deresi (3941'21'”N 26²3'29”E) (Ezine-Çanakkale) 3 birey. 
Cobitis puncticulata Erk'akan, Atalay-Ekmekçi \& Nalbant, 1998

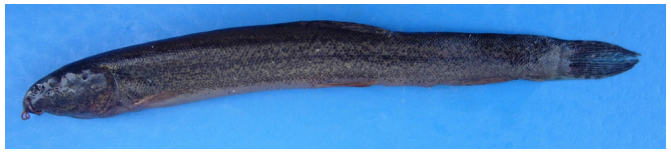

IUCN Kırmızı liste kategorisi: EN B2ab (iii)

Tehditler: Kirlilik.

Tespit edildiği lokaliteler: Manyas Gölü (40¹0'56’N 2752’26”E) (Gölyaka kasabas1) 1 birey.

Cobitis simplicispina Hankó, 1925

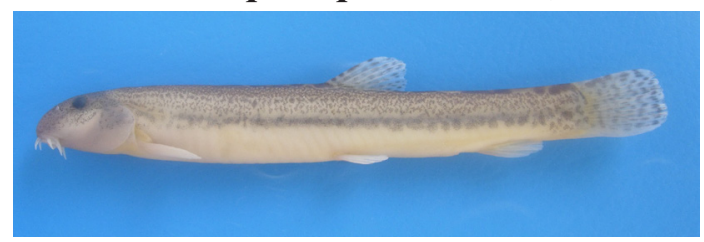

IUCN Kırmızı liste kategorisi: LC

Tehditler: Barajlar, su kaynaklarının kullanımı ve kuraklık.

Tespit edildiği lokaliteler: Saltık Deresi (38²9'05'N 3004'26”E) (Sandıkl1-Afyonkarahisar) 28 birey, Dalaman Çayı $\left(36^{\circ} 49^{\prime} 58^{\prime \prime} \mathrm{N}\right.$ 2847'53'"E) (Dalaman-Muğla) 2 birey, Gölhisar Gölü (3707'04'N 29³6'09”E) (Gölhisar-Burdur) 1 birey, Dalaman Çayı (37¹4'23”N 29॰31'53”E) (Gölhisar-Burdur) 2 birey, Kırkpınar kaynakları (37¹0'52”N 2945'24'"E) (Tefenni-Antalya) 17 birey, Adıyan Çayı $\left(38^{\circ} 15^{\prime} 23^{\prime}\right.$ 'N 31'36'44'”E) (Akşehir-Konya) 4 birey, Kali Çay $\left(38^{\circ} 36^{\prime} 04^{\prime \prime} \mathrm{N}\right.$ 3053'37'”E) (Çay-Afyonkarahisar) 10 birey, Akarçay (3846’40'”N 30 46'50”'E) (Gebeceler-Afyonkarahisar) 1 birey, Salur Deresi

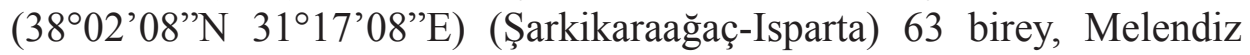
Çayı (38 19'36"N 34¹4'26'E) (Gülağaç-Aksaray) 16 birey, Kökez Deresi (3821'32'N 32¹8'54”'E) (Kadınhan1-Konya) 30 birey.

Familia: Balitoridae

Seminemacheilus lendlii (Hankó, 1925)

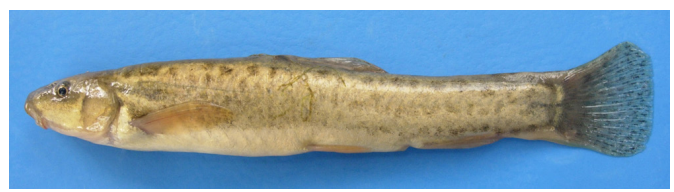


IUCN Kırmızı liste kategorisi: VU A2c

Tehditler: Su kaynaklarının kullanımı, rezervuar yapımı, iklimsel değişimler sonucu yağışların azalması (kuraklık) ve yabancı tür varlığı.

Tespit edildiği lokaliteler: Eğirdir Gölü kaynakları $\left(38^{\circ} 07^{\prime} 55^{\prime}\right.$ N 3046’26”E) (Akkeçili kasabası-Eğirdir) 69 birey.

Familia: Gobiidae

Knipowitschia mermere Ahnelt, 1995

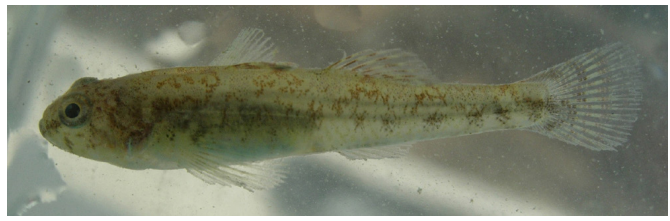

IUCN Kırmızı liste kategorisi: VU B2ab (i,ii,iii,iv,v)

Tehditler: Sınırlı yaşam alanı, habitat kaybı ve yabancı tür varlığı (Sander lucioperca, Carassius gibelio, Atherina boyeri, Pseudorasbora parva).

Tespit edildiği lokaliteler: Marmara Gölü (38³5'42”N 2759'49'E) (Salihli-Manisa) 40 birey.

Familia: Cyprinodontidae Aphanius anatoliae (Leidenfrost, 1912)

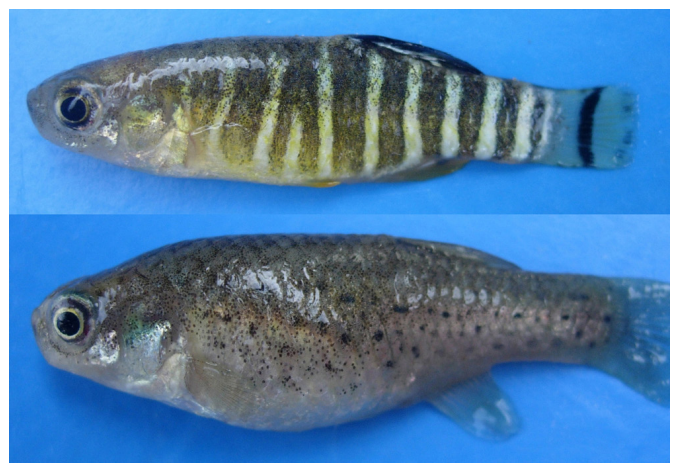

IUCN Kırmızı liste kategorisi: NT

Tehditler: Su kaynaklarının kullanımı ve habitat kaybı

Tespit edildiği lokaliteler: Işıklı kaynakları (38¹9'07’N 2951'12’E)

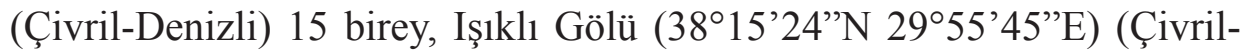
Denizli) 315 birey, Eğirdir Gölü (3807’22’’N 3054’28’'E) (Gelendost- 
Isparta) 7 birey, Aksu kanalı (3750'02'N 3053'56”E) (Eğirdir-Isparta)

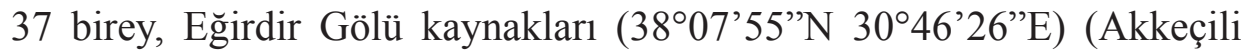

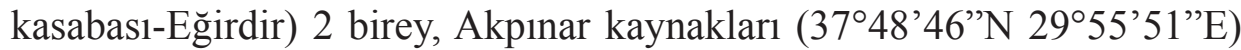
(Başmakçı-Afyon) 17 birey, Sultansazlığı (38 $\left.14^{\prime} 04^{\prime \prime N} 35^{\circ} 13^{\prime} 48^{\prime \prime} \mathrm{E}\right)$ (Yeşilhisar-Kayseri) 66 birey, Büyükçay Deresi (37³2'46”'N 31 $\left.{ }^{\circ} 29^{\prime} 44^{\prime \prime} \mathrm{E}\right)$ (Beyşehir-Konya) 27 birey, İlırmak (37³0’36”N 31 27'26”E) (Beyşehir-

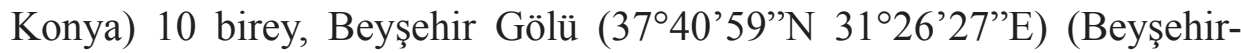
Konya) 9 birey, Kozanl1 Deresi (3902'14'”N 3248'37'E) (Kulu-Konya) 8 birey, Kökez Deresi (38²1'32'” 32¹8'54'E) (Kadınhanı-Konya) 25 birey, Beşgöz kaynakları (38 $16^{\prime} 42^{\prime}$ 'N 32²1’03”E) (Sarayönü-Konya) 15 birey.

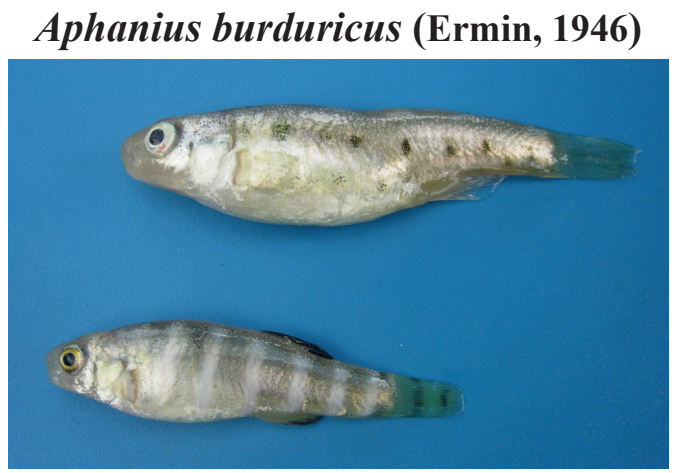

IUCN Kırmızı liste kategorisi: EN A2e

Tehditler: Sınırlı yaşam alanı ve Kirlilik.

Tespit edildiği lokaliteler: Burdur Gölü (3740’46”N 30¹0’28’E) (Burdur) 108 birey.

\section{TARTIŞMA ve SONUÇ}

Orta ve Batı Anadolu içsularından 278 istasyondan toplanan balık örnekleri sonucu 6 familyadan 32 endemik balık türü elde edilmiştir.

Kuru (1994), “Orta Anadolu Göller Bölgesindeki Endemik Balık Türlerinin Korunma Statüleri” konulu çalışmasında, 3 familyadan 13 endemik takson, Balık (1995), Anadolu'nun Ege ve Akdeniz havzaları için 5 familyadan 30 endemik takson, Küçük (2006), Türkiye içsularında 70 endemik takson, Fricke ve diğerleri (2007), Türkiye balıkları kontrol listesinde, 
Türkiye içsuları için 78 taksonun endemik özellikte olduğunu, Geldiay ve Balık (2007), 5 familyadan 41 taksonun Türkiye içsuları için endemik özellik taşıdığını belirtmişlerdir. Froese ve Pauly (2014), Türkiye içsularında 53 endemik taksonun varlığını kabul etmişlerdir.

Çalışmada elde edilen 32 endemik balık türünün devamlılığı üzerindeki kırmızı liste kategorileri incelendiğinde, IUCN (2014)'e göre 6 tür VU, 12 tür EN, 3 tür CR, 7 tür LC, 2 tür DD ve 2 tür NT; Fricke ve diğerleri (2007)'ne gore 11 tür EN, 19 tür CR ve 1 tür DD; Küçük (2006)'e gore 1 tür $\mathrm{DD}, 12$ tür $\mathrm{CR}, 6$ tür VU, 3 tür $\mathrm{EN}, 1$ tür LC, 1 tür NT, Smith ve Darwall (2005)'a göre 6 tür CR, 3 tür VU, 1 tür LC, 9 tür DD ve 3 tür EN olarak sınıflandırıldığ 1 görülmektedir (Tablo 1). Kuru (1994) ise, IUCN 1974'e gore, 12 taksonu I (Indeterminate=Belirsiz), Capoeta pestai türünü ise E (Endangered=Tehlikede) olarak değerlendirmiştir. Çalışmamızda elde edilen birey sayıları ve saha çalışmalarındaki gözlemler ışı̆̆ında söz konusu Kırmızı Liste kategorilerinde değişikliklerin yapılmasının türlerin devamlılığı açısından yararlı olacaktır. Bu bağlamda çalışmada elde edilen türlerden 8'inin yaşadıkları alanların kirlilik, su kaynaklarının aşırı ve bilinçsiz kullanımı ve barajların tehdidi altında oldukları gerekçesiyle CR; 19'unun yaşam alanlarının çok sınırlı olması (birçoğu nokta endemik: sadece bir lokalitede bulunuyor), elde edilen birey sayılarının düşük olması, habitat kayıpları, kirlilik, kuraklık ve barajların tehdidi dolayısıyla EN ve 5 'inin de yukarıda sıralanan tehdit unsurlarına maruz olmalarına rağmen daha geniş dağılım alanlarına sahip olmaları nedeniyle LC lategorilerinde yer almasının türlerin devamlılığ mektedir (Tablo 1). 
Tablo 1. Çalışmada elde edilen endemik balık taksonlarının farklı araştırıcılara göre Kırmızı Liste Kategorileri ve Başlıca Tehditler.

\begin{tabular}{|c|c|c|c|c|c|c|c|}
\hline \multirow[t]{2}{*}{ Tür } & \multirow[t]{2}{*}{$\mathbf{N}$} & \multicolumn{5}{|c|}{ IUCN Kırmızı Liste Kategorisi } & \multirow[t]{2}{*}{ Tehditler } \\
\hline & & 1 & 2 & 3 & 4 & 5 & \\
\hline S. platycephalus & 15 & $\mathrm{CR}$ & $\mathrm{CR}$ & $\mathrm{CR}$ & --- & $\mathrm{CR}$ & YTV, YDA \\
\hline A. baliki & 26 & EN & $\mathrm{EN}$ & VU & --- & $\mathrm{EN}$ & K, B, SKK, Krk. \\
\hline C. antalyensis & 82 & VU & $\mathrm{EN}$ & & --- & EN & $\mathrm{K}, \mathrm{B}$ \\
\hline C. angorae & 901 & $\mathrm{DD}$ & $\mathrm{CR}$ & VU & $\mathrm{DD}$ & $\mathrm{LC}$ & $\mathrm{B}$ \\
\hline C. baliki & 330 & $\mathrm{LC}$ & $\mathrm{DD}$ & --- & --- & $\mathrm{LC}$ & B \\
\hline C. bergamae & 14 & NT & EN & EN & VU & $\mathrm{CR}$ & K, B, SKK, Krk. \\
\hline C. tinca & 574 & $\mathrm{LC}$ & EN & --- & --- & $\mathrm{LC}$ & K, B, SKK, Krk. \\
\hline C. angorense & 6 & $\mathrm{LC}$ & $\mathrm{CR}$ & VU & --- & $\mathrm{EN}$ & $\mathrm{K}, \mathrm{B}$ \\
\hline C. beysehirense & 4 & $\mathrm{EN}$ & $\mathrm{CR}$ & $\mathrm{CR}$ & $\mathrm{EN}$ & $\mathrm{EN}$ & SYA, YTV, Krk. \\
\hline C. fahirae & 93 & $\mathrm{EN}$ & $\mathrm{EN}$ & $\mathrm{CR}$ & $\mathrm{CR}$ & EN & K, SKK, Krk. \\
\hline C. holmwoodii & 139 & $\mathrm{VU}$ & $\mathrm{CR}$ & $\mathrm{CR}$ & $\mathrm{DD}$ & $\mathrm{CR}$ & K, B, SKK, Krk. \\
\hline C. meandrense & 35 & VU & EN & $\mathrm{CR}$ & VU & $\mathrm{CR}$ & K, B, SKK, Krk. \\
\hline G. hettitorum & 12 & $\mathrm{CR}$ & $\mathrm{CR}$ & VU & VU & EN & SYA, Krk. \\
\hline H. kemali & 319 & $\mathrm{EN}$ & $\mathrm{CR}$ & $\mathrm{CR}$ & $\mathrm{CR}$ & $\mathrm{CR}$ & HK, YTV \\
\hline L. mermere & 20 & $\mathrm{DD}$ & $\mathrm{CR}$ & $\mathrm{CR}$ & $\mathrm{DD}$ & EN & SYA, YTV \\
\hline P. anatolicus & 360 & $\mathrm{EN}$ & $\mathrm{CR}$ & EN & EN & EN & SYA, K, Krk. \\
\hline P. antalyae & 129 & $\mathrm{VU}$ & $\mathrm{CR}$ & $\mathrm{VU}$ & DD & $\mathrm{EN}$ & SKK, HD, K \\
\hline P. crassus & 115 & $\mathrm{EN}$ & $\mathrm{EN}$ & $\mathrm{EN}$ & EN & EN & SKK, Krk. \\
\hline P. egridiri & 82 & EN & $\mathrm{CR}$ & $\mathrm{CR}$ & $\mathrm{CR}$ & EN & YTV, Krk. \\
\hline P. fahrettini & 89 & EN & --- & --- & --- & EN & SKK, B, Krk. \\
\hline P. ninae & 97 & $\mathrm{CR}$ & --- & --- & --- & EN & SKK, B, K, Krk. \\
\hline S. elmaliensis & 21 & $\mathrm{EN}$ & $\mathrm{CR}$ & $\mathrm{CR}$ & $\mathrm{DD}$ & EN & SKK, B, Krk. \\
\hline S.anatolicus & 41 & $\mathrm{LC}$ & $\mathrm{CR}$ & & & $\mathrm{EN}$ & --- \\
\hline V. mirabilis & 96 & $\mathrm{LC}$ & EN & $\mathrm{CR}$ & --- & $\mathrm{CR}$ & $\mathrm{K}, \mathrm{B}, \mathrm{SKK}$ \\
\hline C. bilseli & 38 & $\mathrm{EN}$ & $\mathrm{CR}$ & VU & $\mathrm{CR}$ & EN & YTV, Krk. \\
\hline C. fahirae & 116 & $\mathrm{LC}$ & $\mathrm{CR}$ & $\mathrm{LC}$ & $\mathrm{LC}$ & $\mathrm{CR}$ & K, SKK \\
\hline C. puncticulata & 1 & EN & $\mathrm{CR}$ & $\mathrm{DD}$ & $\mathrm{CR}$ & EN & $\mathrm{K}$ \\
\hline C. simplicispina & 187 & $\mathrm{LC}$ & $\mathrm{CR}$ & --- & $\mathrm{DD}$ & $\mathrm{LC}$ & B, SKK, Krk. \\
\hline S. lendlii & 69 & VU & $\mathrm{CR}$ & --- & DD & $\mathrm{CR}$ & SKK, Krk., YTV \\
\hline A. anatoliae & 543 & NT & EN & NT & $\mathrm{DD}$ & $\mathrm{LC}$ & SKK, HK \\
\hline A. burduricus & 108 & $\mathrm{EN}$ & $\mathrm{CR}$ & $\mathrm{CR}$ & $\mathrm{DD}$ & EN & SYA, K \\
\hline K. mermere & 40 & $\mathrm{VU}$ & EN & $\mathrm{CR}$ & $\mathrm{CR}$ & EN & SYA, HK, YTV \\
\hline
\end{tabular}

1: IUCN (2014), 2: Fricke vd., (2007), 3: Küçük (2006), 4: Smith ve Darwall (2005), 5: Önerilen Kategori. 
IUCN Kırmızı Liste Kategorileri: (VU): Hassas (Vulnerable), (EN): Nesli Tehlikede (Endangered), (CR): Kritik Olarak Nesli Tehlikede (Critically Endangered), (NT): Tehlikeye Yakın (Near Threatened), (LC): Az İlgi Duyulan (Least Concern), (DD): Eksik Veri (Data Deficient).

Tehtitler: YDA: Yasadışı avcılık, SYA: Sınırlı yaşam alanı, YTV: Yabancı tür varlığı, YDA: Yasadışı avcılık, HK: Habitat kaybı, B: Barajlar, K: Kirlilik, Krk.: Kuraklık, HD: Habitat değişimi, SKK: Su kaynaklarının kullanımı.

Çalışmaya konu olan endemik balık taksonları için tehdit unsurları arasında, vahşi sulamanın yanısıra son yıllarda yaşanan iklimsel değişimler neticesinde yağış azlığı dolayısıyla artan kuraklık, su kaynaklarının bilinçsiz ve aşırı kullanımı, kirlilik ve barajların mevcudiyeti ön sıralarda yer almaktadır. Ayrıca, özellikle son dönemlerde artış gösteren yabancı türlerin varlığı, sınırlı yaşam alanlarına sahip olmaları, habitat kayıpları, habitat değişimi ve yasadışı avcılık da söz konusu endemik taksonların devamlılığını önemli ölçüde zorlaştırmaktadır. (Şekil 1). Ancak tüm bu olumsuz koşullar göz önüne alındığında, doğal koşullardan ziyade insan müdahelesinin her alanda olduğu gibi burada da en önemli etken olduğu anlaşılmaktadır. Öyleki, son dönemlerde doğal nedenlerin yanısıra yanlış uygulamalarla Akşehir Gölü, Sultan Sazlığı, Avlan Gölü vb. gibi ekosistemler tamamen kurumuş veya kurutulmuş, Beyşehir Gölü ve Tuz Gölü gibi ülkemizin büyük gölleri de kuruma aşamasına gelmiş ve de kirletilmiştir. Yine benzer şekilde, Eğirdir ve Beyşehir gölleri başta olmak üzere birçok sulak alana yapılan yabancı balık aşılamaları (Sander lucioperca, Carassius gibelio, Atherina boyeri, Pseudorasbora parva) olumsuz sonuçlar doğurmuştur. 


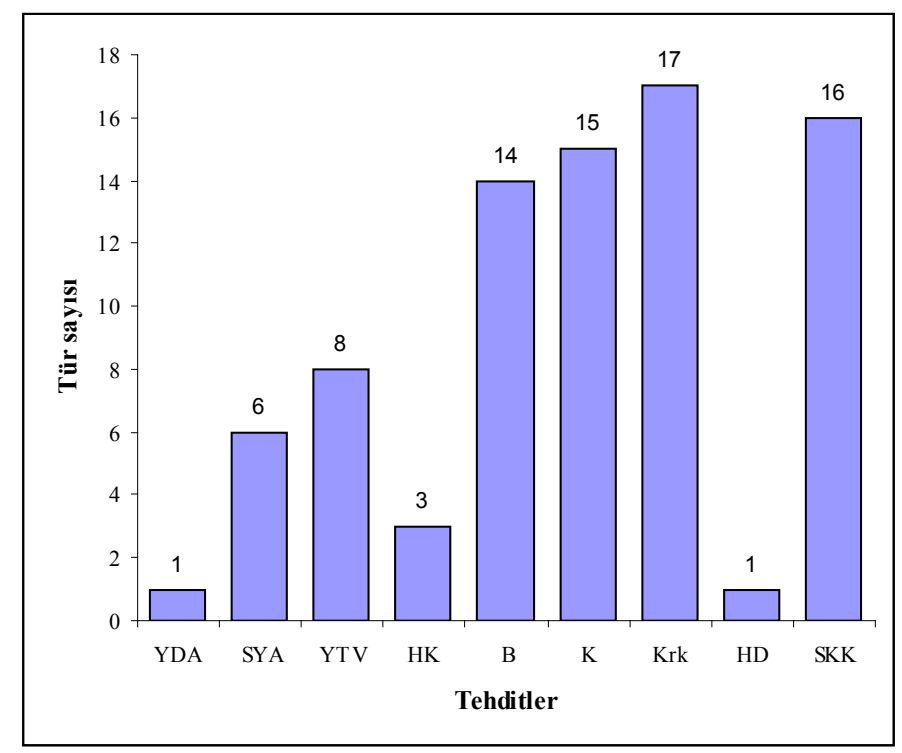

Şekil 1. Türlerin varlı̆̆ını tehdit eden unsurlar (YDA: Yasadışı avcılık,

SYA: Sınırlı yaşam alanı, YTV: Yabancı tür varlı̆̆ı, YDA: Yasadışı avcılık, HK: Habitat kaybı, B: Barajlar, K: Kirlilik, Krk.: Kuraklık, HD: Habitat değişimi, SKK: Su kaynaklarının kullanımı).

Yukarıda bahsedilen olumsuz koşullar nedeni ile Eğirdir Gölü'nde Crossocheilus klatti, Capoeta pestai, Pseudophoxinus egridiri türleri günümüzde ya tamamen yok olmuş ya da populasyonları oldukça zayıflamıştır. Benzer şekilde Beyşehir Gölü'nde de Alburnus akili, Pseudophoxinus battalgili ve Capoeta pestai türleri aynı akıbete uğramıştır. Adı geçen türlerden özellikle Alburnus akili türünün doğada neslinin tükenmiş olduğu ise tüm otoritelerin kabul ettiği üzücü bir sonuçtur.

Sonuç olarak, Türkiye zoocoğrafik konumu ve farklı iklimsel koşulları sebebiyle biyolojik çeşitliliğin oldukça zengin bulunduğu bir ülke konumundadır. Ancak, bu biyolojik çeşitliliğin korunması ve sürdürülebilirliğinin sağlanması çok önemlidir. Bu nedenle, dağılım alanları ve çevresinde yaşayan topluluklar başta olmak üzere, toplumun her kesimine söz konusu balık türleri tanıtılmalı ve konunun hassasiyeti konusunda farkındalık yaratacak faaliyetler düzenlenmelidir. Bu amaçla, ilköğretim seviyesinde okullarda seminerler düzenlenmesi, broşürler hazırlanarak yöre halkının dikkatinin çekilmesi, yerel yönetimlerin konuyu sahiplenmesi için çalış- 
malar yapılması önerilebilir. Koruma kavramının, bir balık bireyinden başlayarak, balığın yaşadığı sucul sisteme ve sonrasında da bölgesel ve hatta ülke çapında toplumun tüm bireylerine kavratılması gerekmektedir. Ancak bu şekilde, sınırlı olan doğal kaynaklarımız verimli ve sürdürülebilir şekilde kullanılabilir.

\section{TEŞEKKÜR}

Bu çalışmanın materyali 2004/SÜF/001 No'lu proje kapsamında toplanmış olup, projeyi destekleyen ege Üniversitesi Bilimsel Araştırmalar Fon Saymanlığına teşekkür ederiz.

\section{KAYNAKLAR}

Ahnelt, H., (1995). Two new species of Knipowitschia ILJIN, 1927 (Teleostei: Gobiidae) from Western Anatolia, Mitteilungen aus dem Hamburgischen Zoologischen Museum und Institute, 92: 155-168.

Balık, S., (1988). Türkiye'nin Akdeniz Bölgesi İçsu Balıkları Üzerinde Sistematik ve Zoocoğrafik Araştırmalar. Doğa TU Zooloji Dergisi, 12 (2): 156-179.

Balık, S., (1995). Freshwater Fish in Anatolia, Turkey, Biological Conservation, 72: 213-223.

Banarescu, P. M., Nalbant, T. T., Balık, S. (1978): Sübwasserfische der Türkei. 11. Teil. Die Gattung Orthrias in der Türkei und in Südbulgarien (Pisces, Cobitidae, Noemacheilinae). Mitteilungen aus dem Hamburgischen Zoologischen Museum und Institute, 75: 255-266.

Battalgil, F., (1944). Türkiye'de Yeni Tatlısu Balıkları. İstanbul Üniversitesi Fen Fakültesi Mecmuası, seri B, cilt IX, say1 2: 126-133.

Bogutskaya, N. G., (1992). A Revision of the Species of the Genus Pseudophoxinus (Leucicinae, Cyprinidae) from Asia Minor, Mitteilungen aus dem Hamburgischen Zoologischen Museum und Institute, 89: 261-290.

Bogutskaya, N.G. (1995). Leuciscus kurui, a new cyprinid fish from the upper Tigris (Dicle) system. Mitteilungen aus dem Hamburgischen Zoologischen Museum und Institute, 92: 149-154.

Bogustkaya, N. G., (1996). Contribution to the knowledge of leuciscinae fishes of the Asia Minor. Part 1.Morfology and taxonomic relationships 
of L. borysthenicus (Kesler, 1859), L. smyrnaeus Boulenger, 1896 and Ladigesocypris ghigii (Gianferrari,1927) (Cyprinidae:Pisces), Pulicación Especial del Instituto Español de Oceanografía, 21: 25-44.

Bogustkaya, N. G., (1997a). Chondrostoma beysehirense, a new cyprinid fish from Beyşehir Lake, Central Turkey, Ichthyological Exploration of Freshwaters, 8 (2): 151-158.

Bogutskaya, N.G., (1997b). Contribution to the knowledge of leuciscine fishes of Asia Minor. Part. 2. An annotated check-list of leuciscine fishes (Leuciscinae, Cyprinidae) of Turkey with description of a new species and two new subspecies. Mitteilungen aus dem Hamburgischen Zoologischen Museum und Institute, 94: 161-186.

Bogutskaya, N. G., Küçük, F., Ünlü, E., (2000). Alburnus baliki, a new species of Cyprinid from Manavgat River system, Turkey, Ichthyological Exploration of Freshwaters, 11 (1): 55-64.

Demirsoy, A., (2002). Genel Zoocoğrafya ve Türkiye Zoocoğrafyası "Hayvan Coğrafyası", Meteksan A. Ş. Ankara, 1007 s.

Deyrolle, M. T. (1872). Notice sur une Espece Remarquable de Poisson qui vit Dans les eaux du lac de van. Revue et Magasin de Zoologie, 2 serie, T. XXIII, 401-406.

Elvira, B., (1987). Taxonomic revision of the genus Chondrostoma Agassiz, 1835 (Pisces, Cyprinidae), Cybium, 11 (2): 111-140.

Erk'akan, F. (1983). The Fishes of the Thrace Region. Hacettepe Bulletin of Natural Sciences and Engineering, 12: 39-48.

Erkakan, F., Atalay-Ekmekçi, F. G., Nalbant, T. T., (1999). A review of the genus Cobitis in Turkey (Pisces: Ostariophysi: Cobitidae), Hydrobiologia, 403: 13-26.

Freyhof, J., Özuluğ, M., (2006). Pseudophoxinus ninae, a new species from Central Anatolia, Turkey (Teleostei: Cyprinidae), Ichthyological Exploration of Freshwaters, 17 (3): 255-259.

Freyhof, J., Özuluğ, M., (2009). Pseudophoxinus fahrettini, a new species of spring minnow from Central Anatolia (Teleostei: Cyprinidae), Ichthyological Exploration of Freshwaters, 20 (4): 325-332.

Fricke, R., Bilecenoğlu, M., Sarı, H. M., (2007). Annotated checklist of fish and lamprey species (Gnathostomata and Petromyzontomorphi) of Turkey, including a Red List of threatened and declining species, Stuttgarter Beiträge zur Naturkunde, A, 706, 169 p. 
Geldiay, R., Balık, S., (2007). Türkiye Tatlısu Balıkları, Ege Üniversitesi Su Ürünleri Fakültesi Yayınları No:46, (5. bask1), Ege Üniversitesi Basımevi, Bornova-İzmir, $644 \mathrm{~s}$.

Karaman, M. S., (1969). Revision der Kleinasiatischen und Vorderasiatischen Arten der Genus Copoeta (Varicorhinus partim), Mitteilungen aus dem Hamburgischen Zoologischen Museum und Institute, 66: 17-54.

Karaman, M. S., (1971). Susswasserfische der Turkei, 8. Teil. Revision der Barben Europas. Vorderasien un Nordafrikans, Mitteilungen aus dem Hamburgischen Zoologischen Museum und Institute, 67: 175-254.

Kuru, M. (1980). Key to Inland Water Fishes of Turkey, Hacettepe Bulletin of Natural Sciences and Engineering, 9: 103-133.

Kuru, M., (1994). Conservation Status of Endemic Fish Species of Central Anatolian Lakes, E.U.F.F. Journal B, Supplement 16/1: 897-902.

Küçük, F., (2006). Türkiye'deki Bazı Endemik İçsu Balıklarının Dünya Doğayı Koruma Birliği (IUCN) Ölçütlerine Göre Değerlendirilmesi, I. Ulusal Balıklandırma ve Rezervuar Yönetimi Sempozyumu, 7-9 Şubat 2006, 151-159, Antalya.

Küçük, F., İkiz, R., (1993). Determination of Fish Species in Aksu Stream and It's Branches (Antalya), Turkish Journal of Zoology, 17: 427-443.

Küçük, F., İkiz, R., (2004). Antalya Körfezi'ne Dökülen Akarsuların Balık Faunas1, Ege Üniversitesi Su Ürünleri Dergisi, 21 (3-4): 287-294.

Smith, G. K., Darwall, R. T. W., (2005). The status and distribution of freshwater fish endemic to the Mediterranean Basin, IUCN Freshwater Biodiversity Assessment Programme, $31 \mathrm{p}$.

Turan, D., Kottelat, M., Ekmekçi, F. G., İmamoğlu, H. O., (2006). A review of Capoeta tinca, with descriptions of two new species from Turkey (Teleostei: Cyprinidae), Revue Suisse de Zoologie, 113 (2): 421-436.

Wildekamp, R. H., Küçük, F., Ünlüsayın, M., Neer, W. V., (1999). Species and Subspecies of the Genus Aphanius Nardo 1897 (Pisces: Cyprinodontidae) in Turkey, Turkish Journal of Zoology, 23: 23-44.

Yeğen, V., Balık, S., Bilçen, E., Sarı, H. M., Uysal, R., İlhan, A., Bostan, H., (2007). Afyon İli Akarsularında Yayılış Gösteren Balık Türleri ve Dağılımları, Türk Sucul Yaşam Dergisi Ulusal Su Günleri 2007, 3-5 (5-8): 419-428.

Yeğen, V., Balık, S., Bilçen, E., Sarı, H. M., Uysal, R., Yağc1, A., (2008). 
Denizli İli Akarsularında Yayılım Gösteren Balık Türleri ve Bölgedeki Dağılımları, Journal of Fisheriessciences.Com, 2 (3): 301-311.

Froese, R., Pauly, D., (2015). FishBase. World Wide Web electronic publication. www.fishbase.org, version (04/2015).

IUCN 2014. The IUCN Red List of Threatened Species. Version 2015.2. $<$ http://www.iucnredlist.org $>$. Downloaded on 24 June 2015. 